Tabea Gubler, Franziska Krähenmann, Malgorzata Roos, Roland Zimmermann

and Nicole Ochsenbein-Kölble*

\title{
Determinants of successful breastfeeding initiation in healthy term singletons: a Swiss university hospital observational study
}

\section{Abstract}

Aims: Breastfeeding significantly benefits mothers and infants. We aimed to identify the determinants of its successful initiation.

Methods: A retrospective study of 1893 mothers delivering healthy term singletons at a Swiss university hospital from 1/2008 to 3/2009 determined the associations between multiple breastfeeding and early postpartum parameters by univariate and multiple regression analysis.

Results: Multiparity was associated with nursing exclusively at the breast at discharge $(\mathrm{P}<0.001)$, less use of maltodextrin supplement $(\mathrm{P}<0.05)$, bottle/cup (both $\mathrm{P}<0.001)$, but more pacifier use $(\mathrm{P}<0.05)$. Among obese mothers, nursing exclusively at the breast at discharge was less frequent, and use of all feeding aids more frequent, than among normal-weight women (both $\mathrm{P}<0.001$ ). Neuraxial anesthesia was associated with use of maltodextrin and bottle (both $\mathrm{P}<0.05$ ) compared to no anesthesia. Delayed first skin-to-skin contact and rooming-in for $<24 \mathrm{~h}$ /day were each associated with maltodextrin and cup $(\mathrm{P}<0.05)$. Nursing exclusively at the breast at discharge was less frequent $(\mathrm{P}<0.001)$, and bottle use more frequent $(\mathrm{P}<0.05)$, in women with sore nipples than in those without.

Conclusions: Obesity is a potent inhibitor of breastfeeding initiation. Delivery without anesthesia by a multiparous normal-weight mother, followed by immediate skin-toskin contact, rooming-in for $24 \mathrm{~h} /$ day, and dedicated nipple care, provides the best conditions for successful early postpartum breastfeeding without the need for feeding aids or nutritional supplements.

Keywords: Breastfeeding; obesity; obstetric anesthesia; postpartum period; rooming-in; skin-to-skin contact.

\footnotetext{
*Corresponding author: Nicole Ochsenbein-Kölble, Obstetric Research Unit, Department of Obstetrics, Zurich University Hospital, Frauenklinikstr. 10, CH-8091 Zurich, Switzerland,

Tel.: +41-1-255-5101, Fax: +41-1-255-5107,

E-mail: Nicole.Ochsenbein@usz.ch
}

Tabea Gubler: Obstetric Research Unit, Department of Obstetrics, Zurich University Hospital, Zurich, Switzerland Franziska Krähenmann: Obstetric Research Unit, Department of Obstetrics, Zurich University Hospital, Zurich, Switzerland Malgorzata Roos: Division of Biostatistics, Institute of Social and Preventive Medicine (ISPM), Zurich University Hospital, Zurich, Switzerland

Roland Zimmermann: Obstetric Research Unit, Department of Obstetrics, Zurich University Hospital, Zurich, Switzerland

\section{Introduction}

It is increasingly difficult to ignore the benefits of breastfeeding for both infants and mothers [15]. Breastfeeding decreases the risk of sudden infant death [8], necrotizing enterocolitis, and other neonatal infections [14], while protecting against cardiovascular disease [27], atopic disease [33], and obesity [10]. It may even improve cognitive development [3]. Maternal benefits include reduced cancer risk of both breast [9] and ovary [31], and easier weight loss after pregnancy [4].

The general recommendation to breastfeed is thus beyond dispute. The World Health Organization (WHO) recommends exclusive breastfeeding for the first 6 months, continued with appropriate supplements for 2 years or more [35].

Research has intensified into the factors that inhibit or facilitate breastfeeding. The main risk factors for shorter or non-initiated breastfeeding are maternal obesity [2], high gestational weight gain (GWG) [16], low social status [12], epidural anesthesia during labor [37], cesarean section [32], and delayed skin-to-skin contact [24].

As for positive factors, we know that experience of successful initiation of breastfeeding in the immediate postpartum period, when motivation is readily boosted or destroyed, is crucial for further breastfeeding behavior [13]. The supportive setting of a "baby friendly hospital" promotes longer breastfeeding [22]. In order to optimize these factors, we wished to identify and measure the determinants of successful breastfeeding initiation in the 
immediate postpartum period, before mother and baby leave the hospital.

\section{Materials and methods}

\section{Design and population}

From the 2886 births between 1 January 2008 and 31 March 2009 in the Division of Obstetrics at Zurich University Hospital, Switzerland, our retrospective study identified 1893 healthy singleton term infants and mothers with no contraindications to breastfeeding (exclusion criteria: Figure 1).

\section{Parameters}

We analyzed three sets of parameters relating to mother, infant, and postpartum period.

Maternal parameters were age at delivery, parity, prepregnant body mass index (BMI), GWG, smoking during pregnancy, ethnicity, marital status, socioeconomic status, delivery mode, anesthesia during labor, and postpartum hemoglobin (Hb). Prepregnant BMI was subdivided using the WHO classification [36] and GWG using the Institute of Medicine guideline [17] (Table 1). GWG was calculated only if the woman was weighed $<7$ days prepartum. "Smoking during pregnancy" included all women reporting having smoked at any time during pregnancy regardless of duration. Maternal profession was classified according to "social prestige" as "upper” (physicians, nurses, academic workers, schoolteachers, students), "intermediate" (social workers, technicians, accountants, secretaries), "basic"

\begin{tabular}{lrr} 
& Body mass index, $\mathbf{~ k g} / \mathbf{m}^{2}$ & Total weight gain, $\mathbf{~ g g}$ \\
\hline Underweight & $<18.5$ & $12.7-18.1$ \\
Normal & $18.5-24.9$ & $11.3-15.9$ \\
Overweight & $25-30$ & $6.8-11.3$ \\
Obese & $\geq 30$ & $5.0-9.0$ \\
\hline
\end{tabular}

Table 1 Institute of Medicine recommendations for gestational weight gain [17] per World Health Organization class of body mass index [36].

(clerks, sales and service personnel, craftsmen), "lower" (cleaners, laborers), and "unemployed or homemaker". Delivery was classified as "spontaneous vaginal", "assisted vaginal", "elective cesarean", and "emergency cesarean", and anesthesia as "none", "local", "neuraxial", and "general". High blood loss was defined as a postpartum $\mathrm{Hb}$ level of $<9.5 \mathrm{~g} / \mathrm{dL}$.

Infant parameters were gestational age at birth, sex, birthweight, 5-min Apgar score, umbilical artery $\mathrm{pH}$, and weight at discharge. Infants with an Apgar score $\leq 7$ and/or $\mathrm{pH}<7.15$ were defined as "poorly adapted". Weight change was defined as the difference between birthweight and weight at discharge.

Postpartum parameters were time to first skin-to-skin contact, time of first suckling, and length of rooming-in (for analysis of early bonding). Rooming-in was defined as occupation of the same room by mother and baby during hospital stay. Although assessed in three categories (Table 2), these parameters were simplified into two categories for the regression analyses: time to first skin-to-skin contact was simplified to "within 5 min" or "later", first suckling to "within $1 \mathrm{~h}$ of birth" or "later", and rooming-in to "every night and every day" or " $<24 \mathrm{~h}$ a day".

Other postpartum parameters were length of hospital stay, defined by the number of days postpartum before mother and infant were discharged, and nipple status at discharge.

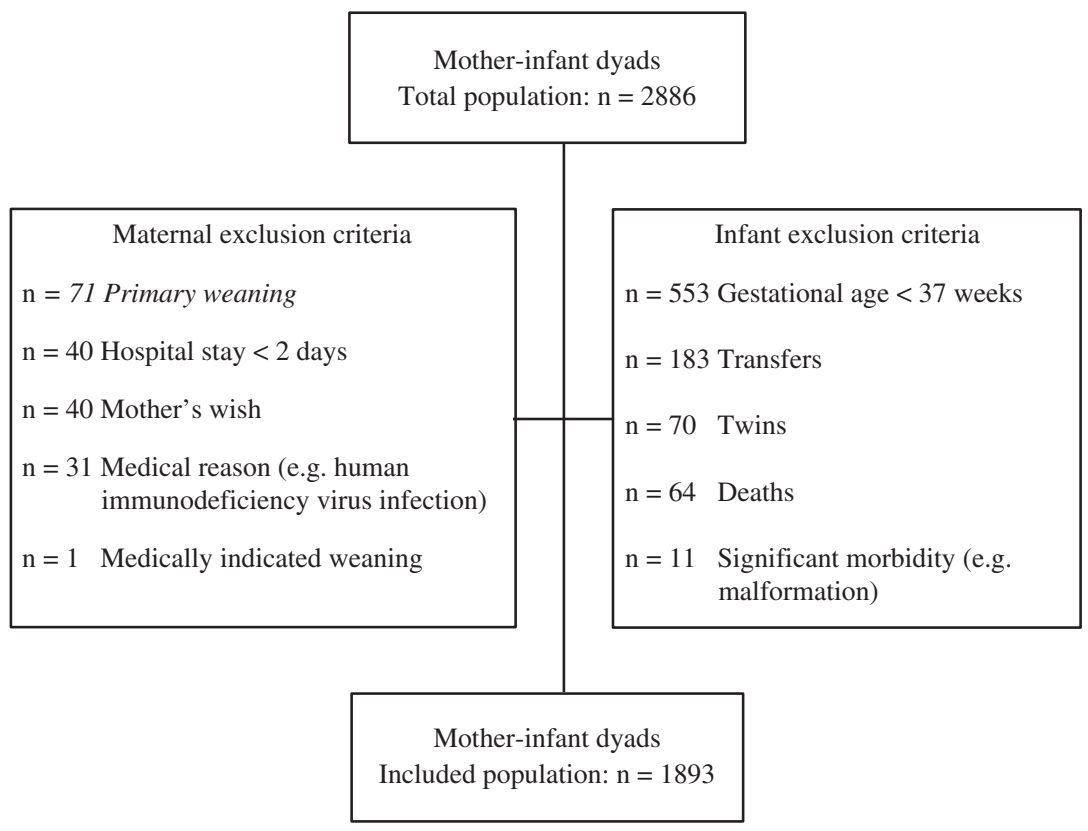

Figure 1 Preselected and selected populations, with maternal and infant exclusion criteria. Total criteria counts are shown, but several dyads accumulated more than one criterion: 993 dyads were excluded. 


\begin{tabular}{|c|c|c|c|}
\hline Characteristics of early postpartum period & Total $\mathbf{n}$ & n (\%) & Mean (SD) \\
\hline Length of hospital stay, days & 1893 & & $4.27(1.18)$ \\
\hline Elective cesarean & & & $5.09(1.07)$ \\
\hline Assisted vaginal & & & $4.16(1.00)$ \\
\hline Emergency cesarean & & & $5.12(1.07)$ \\
\hline Spontaneous vaginal & & & $3.72(0.92)$ \\
\hline First skin-to-skin contact, min & 1871 & & \\
\hline$<5$ & & $1094(58.5)$ & \\
\hline $5-60$ & & $712(38.1)$ & \\
\hline$>60$ & & $65(3.5)$ & \\
\hline First suckling, $\min$ & 1859 & & \\
\hline$<60$ & & $1624(87.4)$ & \\
\hline $60-120$ & & $179(9.6)$ & \\
\hline$>120$ & & $56(3.0)$ & \\
\hline Rooming-in, h/day & 1837 & & \\
\hline 24 & & $1522(82.9)$ & \\
\hline$<24$ & & $315(17.1)$ & \\
\hline Sore nipples at discharge & 1871 & $570(30.5)$ & \\
\hline
\end{tabular}

Table 2 Early postpartum period characteristics.

Based on the 10 steps of successful breastfeeding of the Baby Friendly Hospital Initiative (BFHI), including steps 6 - "Give newborn infants no food or drink other than breast-milk unless medically indicated" - and 9 - "Give no pacifiers or artificial nipples to breastfeeding infants" [34], successful initiation of breastfeeding was analyzed using the following outcome variables: nursing exclusively at the breast at discharge (defined as breast milk only without pumping at all, with no supplements except vitamins $\mathrm{K}$ and $\mathrm{D}$ and medications), and use of bottle, cup, pacifier, nipple shield, and/or maltodextrin nutritional supplement anytime during hospital stay. Maltodextrin was applied by cup and in a second step by bottle if cup application was unsuccessful. Formula milk was just given after prescription of the neonatologist by bottle. Only on demand of the parents were pacifiers given to the newborn owing to step 9 of the BFHI. Breastfeeding at discharge was classified as "nursing exclusively at the breast" or "non-nursing exclusively at the breast". "Nonnursing exclusively at the breast" was defined as breastfeeding with application of breast milk after pumping or with use of nutritional supplements.

Data were processed using perinat, an in-house clinical information system, version 5.0 [38].

\section{Ethical approval}

Data analysis was anonymized; the study was approved by the institutional review board.

\section{Data analysis}

The data were coded in Microsoft Excel 2000 (Redmond, WA, USA) and analyzed using SPSS version 18 (SPSS, Inc., Chicago, IL, USA). Descriptive statistics are presented as mean \pm standard deviation (SD) for continuous variables and as relative frequencies for discrete variables. Univariate and multiple logistic regression analyses were cal- culated for outcome variables. Odds ratios (OR) and 95\% confidence intervals (CI) were provided. The multiple regression model included the following independent variables: multiparity, prepregnant BMI, GWG, birth weight, delivery mode, anesthesia, $\mathrm{Hb}<9.5 \mathrm{~g} / \mathrm{dL}$, length of hospital stay, sore nipples, first skin-to-skin contact, first suckling, and rooming-in. These variables were chosen for their clinical relevance and based on the results of the univariate logistic regression analysis. Length of hospital stay was included in the multiple regression analysis to reduce its bias on the results of the other variables. Additional multiple regression analysis included infant sex. A significance level of $<0.05$ was used throughout.

\section{Results}

\section{Descriptive data}

Table 3 presents the descriptive analysis of maternal characteristics. Mean gestational age at birth was 39.6 \pm 1.2 weeks with a birth weight of $3398 \pm 444 \mathrm{~g}$ and a discharge weight of $3257 \pm 426 \mathrm{~g}$. Fifty-one percent of newborns were male. The mean Apgar at 5 min was $8.9 \pm 0.5$ with a mean umbilical artery $\mathrm{pH}$ of $7.28 \pm 0.07$. The rate of poorly adapted newborns was $4.8 \%$.

The early postpartum period characteristics are shown in Table 2 with frequencies of the breastfeeding initiation parameters presented in Table 4.

\section{Univariate regression analysis}

Multiparous mothers nursed more exclusively at the breast at discharge and used less bottles, cups, and maltodextrin 


\begin{tabular}{|c|c|c|c|}
\hline Maternal characteristics & Total $\mathbf{n}$ & n (\%) & Mean (SD) \\
\hline Age, years & 1893 & & $30.79(5.56)$ \\
\hline Parity & 1893 & & $1.72(0.90)$ \\
\hline Primiparae & 1893 & $942(49.8)$ & \\
\hline Multiparae & 1893 & $951(50.2)$ & \\
\hline Prepregnant body mass index, $\mathrm{kg} / \mathrm{m}^{2}$ & 1820 & & $22.83(4.01)$ \\
\hline Underweight $(<18.5)$ & & $134(7.4)$ & \\
\hline Normal weight (18.5-24.9) & & $1288(70.8)$ & \\
\hline Preobese $(25-30)$ & & $284(15.6)$ & \\
\hline Obese $(\geq 30)$ & & $114(6.3)$ & \\
\hline Gestational weight gain (kg) per Institute of Medicine guideline & 1449 & & $15.03(5.69)$ \\
\hline Below & & $287(19.9)$ & \\
\hline Within & & 461 (31.9) & \\
\hline Above & & $697(48.2)$ & \\
\hline Smoking during pregnancy & 1893 & $198(10.5)$ & \\
\hline Ethnicity & 1893 & & \\
\hline Black & & $120(6.3)$ & \\
\hline Hispanic & & $157(8.3)$ & \\
\hline Asiatic & & $168(8.9)$ & \\
\hline Caucasian & & $1448(76.5)$ & \\
\hline Married & 1893 & $1524(80.5)$ & \\
\hline “Social prestige" & 1890 & & \\
\hline Upper & & $560(29.6)$ & \\
\hline Intermediate & & $281(14.9)$ & \\
\hline Basic & & $345(18.3)$ & \\
\hline Lower & & $218(11.5)$ & \\
\hline Unemployed or homemaker & & $486(25.7)$ & \\
\hline Delivery mode & 1893 & & \\
\hline Spontaneous vaginal & & $1019(53.8)$ & \\
\hline Assisted vaginal & & $211(11.1)$ & \\
\hline Elective cesarean & & $343(18.1)$ & \\
\hline Emergency cesarean & & $320(16.9)$ & \\
\hline Anesthesia & 1871 & & \\
\hline None & & $234(12.4)$ & \\
\hline Local & & $500(26.7)$ & \\
\hline Neuraxial & & $1095(58.5)$ & \\
\hline General & & $42(2.2)$ & \\
\hline Postpartum hemoglobin $<9.5 \mathrm{~g} / \mathrm{dL}$ & 1893 & $231(12.2)$ & \\
\hline
\end{tabular}

Table 3 Maternal characteristics.

than primiparous women $(\mathrm{P}<0.001)$. In contrast, they used more pacifier compared with primiparous mothers $(\mathrm{P}<0.001)$.

Mothers with a normal prepregnant BMI nursed more exclusively at the breast $(\mathrm{P}<0.001)$ and used bottles $(\mathrm{P}<0.001)$, pacifiers $(\mathrm{P}<0.05)$, and maltodextrin $(\mathrm{P}<0.05)$ less frequently than mothers who were obese before pregnancy. Women with excessive GWG nursed less exclusively at the breast and used bottle more often compared with women with normal weight gain $(\mathrm{P}<0.05)$.

Smoking during pregnancy and marital status showed no influence on the evaluated breastfeeding initiation markers. No difference in nursing exclusively at the breast was found depending on the social prestige.
Elective $(\mathrm{P}<0.05)$ and emergency $(\mathrm{P}<0.001)$ cesarean sections were associated with less nursing exclusively at the breast at discharge compared with spontaneous vaginal deliveries.

Neuraxial anesthesia was associated with an unfavorable breastfeeding initiation for the parameters nursing exclusively at the breast and use of bottle, cup, and maltodextrin compared with labor without any anesthesia $(P>0.001)$. After general anesthesia, bottle $(\mathrm{P}<0.05)$, pacifier $(\mathrm{P}<0.05)$, and maltodextrin $(\mathrm{P}<0.001)$ were more often given compared with labor without any anesthesia.

A Hb level of $<95 \mathrm{~g} / \mathrm{L}$ postpartum was associated with less nursing exclusively at the breast at discharge $(\mathrm{P}<0.05)$ 


\begin{tabular}{lrr} 
Breastfeeding initiation & Total $\mathbf{n}$ & $\mathbf{n}(\%)$ \\
\hline $\begin{array}{l}\text { Use of breastfeeding aids during } \\
\text { hospital stay }\end{array}$ & 1857 & \\
$\quad$ Bottle & & $723(38.9)$ \\
$\quad$ Pacifier & & $180(9.7)$ \\
Cup & & $828(44.6)$ \\
$\quad$ Nipple shield & 1890 & $18(1.0)$ \\
Maltodextrin use postpartum & 1609 & $316(19.6)$ \\
$\quad$ Day 1 & 1749 & $767(43.9)$ \\
Day 2 & 1722 & $715(41.5)$ \\
Day 3 & 1617 & $361(22.3)$ \\
After day 3 & 1507 & $48(3.2)$ \\
$\quad$ At discharge & 1891 & \\
Breastfeeding at discharge & & $1279(67.6)$ \\
$\quad$ Nursing exclusively at the breast & & $586(31.0)$ \\
$\quad$ Non-exclusively nursing at the breast & & $26(1.4)$ \\
$\quad$ Weaned & & \\
\hline
\end{tabular}

Table 4 Breastfeeding initiation: descriptive statistics.

and with more use of bottle $(\mathrm{P}<0.001)$, cup $(\mathrm{P}<0.05)$, and maltodextrin $(\mathrm{P}<0.001)$. Male newborns received pacifiers more often than female newborns $(\mathrm{P}<0.05)$.

First physical contact within the first 5 min postpartum $(\mathrm{P}<0.001)$, first suckling $(\mathrm{P}<0.05)$, and rooming-in for $24 \mathrm{~h}(\mathrm{P}<0.05)$ were associated with higher rates of nursing exclusively at the breast at discharge and with less use of bottle and maltodextrin for all three parameters $(\mathrm{P}<0.001)$.

Women with sore nipples nursed less exclusively at the breast at discharge $(\mathrm{P}<0.001)$ and used bottles more often $(\mathrm{P}<0.05)$.

\section{Multiple regression analysis}

Multiple regression analysis (Table 5) showed that nursing exclusively at the breast at discharge was more common among multiparous women (OR=2.11; 95\% CI 1.61-2.76; $\mathrm{P}<0.001)$ than among primiparous women and that they used less maltodextrin $(\mathrm{OR}=0.67$; $95 \% \mathrm{CI} 0.52-0.86$; $\mathrm{P}<0.05)$ and fewer bottles (OR=0.59; 95\% CI 0.45-0.76; $\mathrm{P}<0.001)$ or cups $(\mathrm{OR}=0.64 ; 95 \% \mathrm{CI} 0.50-0.82$; $\mathrm{P}<0.001)$. However, they used pacifiers more often $(\mathrm{OR}=1.88 ; 95 \% \mathrm{CI}$ 1.23-2.86; $\mathrm{P}<0.05)$.

A normal prepregnant BMI correlated with nursing exclusively at the breast at discharge compared to preobesity (OR=0.71; 95\% CI $0.51-0.98 ; \mathrm{P}<0.05)$ or obesity $(\mathrm{OR}=0.31 ; 95 \%$ CI $0.20-0.49 ; \mathrm{P}<0.001)$. More prepregnant obese women also used bottles (OR=3.01; 95\% CI 1.89-4.78; $\mathrm{P}<0.001)$ and maltodextrin $(\mathrm{OR}=2.39 ; 95 \% \mathrm{CI}$ 1.45-3.93; $\mathrm{P}<0.001)$ than normal-weight women.

More women needing neuraxial anesthesia during labor used maltodextrin (OR=1.63; 95\% CI 1.07-2.49;
$\mathrm{P}<0.05)$ and bottles $(\mathrm{OR}=1.72$; 95\% CI 1.07-2.75; $\mathrm{P}<0.05)$ than those receiving no anesthesia. Birthweight was significantly associated with use of a pacifier $(\mathrm{OR}=1.54 ; 95 \%$ CI 1.02-2.33; $\mathrm{P}<0.05)$ and maltodextrin $(\mathrm{OR}=1.40 ; 95 \%$ CI 1.07-1.84; $\mathrm{P}<0.05$ ); incorporation of sex in the analysis abolished the association between pacifier use and birthweight, replacing it with a significant association between pacifier use and male sex $(\mathrm{OR}=1.48$; 95\% CI 1.012.16; $\mathrm{P}<0.05)$ : significantly more male infants required pacifiers.

Delayed first skin-to-skin contact was associated with more use of maltodextrin (OR=1.40; 95\% CI 1.00-1.97; $\mathrm{P}<0.05)$ and cups $(\mathrm{OR}=1.60 ; 95 \%$ CI 1.15-2.23; $\mathrm{P}<0.05)$. However, there was no significant association between first suckling and breastfeeding initiation.

Rooming-in for $<24 \mathrm{~h} /$ day was associated with more use of maltodextrin ( $\mathrm{OR}=1.57$; 95\% CI 1.14-2.16; $\mathrm{P}<0.05)$, cups (OR=1.62; 95\% CI 1.21-2.19; $\mathrm{P}<0.05)$, and bottles (OR=1.54; 95\% CI 1.13-2.08; $\mathrm{P}<0.05)$.

Nipple status correlated with breastfeeding initiation: among women with sore nipples, nursing exclusively at the breast at discharge was less frequent ( $\mathrm{OR}=0.62 ; 95 \%$ CI $0.48-0.80 ; \mathrm{P}<0.001$ ), and bottle use more frequent (OR=1.29; 95\% CI 1.01-1.66; $\mathrm{P}<0.05)$, than among those without sore nipples.

\section{Discussion}

\section{Key results}

Multiparous women and those of normal prepregnant weight initiated breastfeeding more successfully than primiparous women or women with a BMI $>25 \mathrm{~kg} / \mathrm{m}^{2}$. Early mother-infant contact was an equally important positive determinant. Neuraxial anesthesia during labor, in contrast, impaired breastfeeding initiation, as did nipple soreness, emphasizing the importance of careful training in latching on.

\section{Interpretation}

Not unexpectedly, multiparous mothers found it easier to initiate breastfeeding than their primiparous counterparts. However, they used a pacifier significantly more often. The relationship between breastfeeding and pacifier use remains uncertain. Two recent meta-analyses published the same year reached different conclusions, one covering the MEDLINE database from 1980 to 2006 and finding 


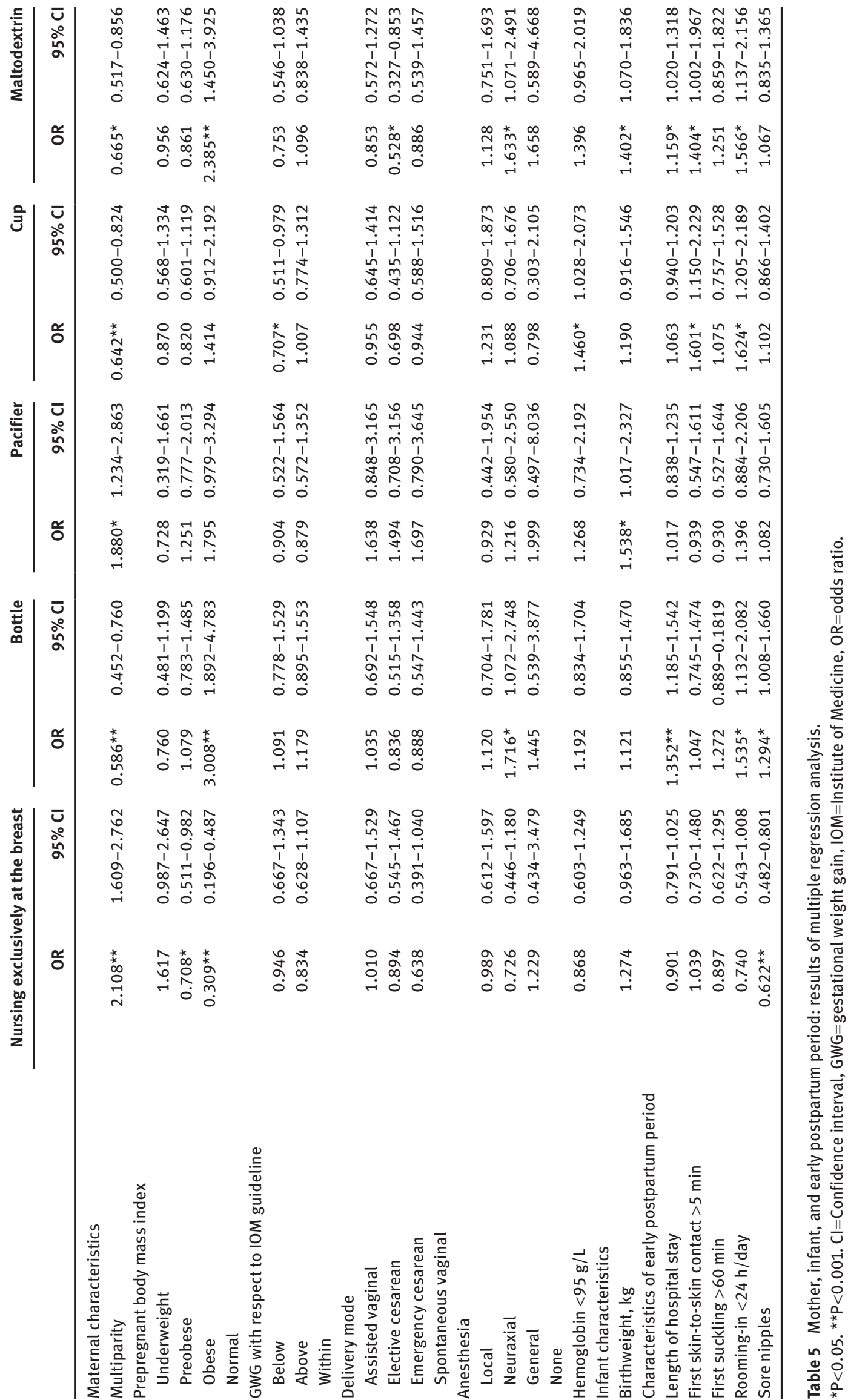


an association between pacifier use and shortened duration of breastfeeding [18], and the other going back to 1950 and covering several additional databases, and concluding that the association is artifactual and probably reflects other complex factors, such as breastfeeding difficulties or intent to wean [26]. Pacifier use is thought to reduce the risk of sudden infant death [21].

Obesity is strongly associated with difficulties with breastfeeding initiation. Nursing exclusively at the breast at discharge was three times more frequent among normalweight than among obese women after correction for other variables. Given that obesity has become a major problem in Western and emerging society, and that the children of obese mothers are at higher risk of developing obesity themselves [28], this finding is highly relevant for clinical practice: breastfeeding may reduce the risk of obesity in the infants of obese mothers. It is essential to raise awareness among health professionals so that they treat obese women with particular care and provide them with evidence-based advice on breastfeeding initiation. Our results confirm those of other studies on the association between obesity and a failure to initiate and sustain breastfeeding [2]. Obese mothers not only breastfeed less and more briefly than normal-weight mothers but also have more difficulty in initiating breastfeeding, suggesting that many leave the maternity ward with low self-confidence in their ability to breastfeed owing to negative early experience. This accords with the observation that obese mothers not only are more likely to perceive their milk supply as inadequate but also are less likely to seek specialist support [23]. Reasons for the association between obesity and poor breastfeeding initiation include the biological, psychological, and mechanical: from a lowered prolactin response to suckling [30] and delayed lactogenesis II [29], through an association between obesity and risk of postpartum depression [20], to the difficulty of latching on to a large breast [19] or a possibly higher rate of inverted nipples.

Neuraxial anesthesia was independently associated with maltodextrin and bottle use. This is difficult to explain, but associations between epidural anesthesia and altered breastfeeding initiation are well documented $[7,37]$. Women prepared to deliver without anesthesia may be expected to breastfeed without recourse to feeding aids. Nevertheless, these findings are remarkable given the variables included in the analysis.

High blood loss during labor showed very few significant correlations with breastfeeding initiation parameters in multiple compared to univariate regression analysis. On this basis, and in this population, it had no independent impact on breastfeeding initiation.
Pacifier use was significantly more frequent in male infants, for no obvious reason. Perhaps they were felt to cry more loudly and/or mothers behaved differently towards them.

Early skin-to-skin contact and rooming-in for $24 \mathrm{~h} /$ day were important factors for successful breastfeeding initiation without recourse to feeding aids. They confirmed the documented influence of maternity ward practice [13]. Not only do baby-friendly hospital initiatives have benefits in terms of breastfeeding but also most mothers welcome the opportunity of keeping their baby with them day and night [25].

Confirmation that sore nipples are a risk for early cessation of breastfeeding [1] emphasizes the importance of prevention, with particular respect to careful training in latching on [5].

The stronger points of our study are the unusually high number of mother-infant dyads and the multiplicity of robustly documented parameters, which combine to increase the value and transferability of the results. In addition, we also qualified breastfeeding initiation with the other documented variables of cup, bottle, and maltodextrin. Compared with other studies using usually the WHO definition of "exclusive breastfeeding" (=breastfed with breast milk including expressed milk or from a wet nurse) [35], we used a particularly strict definition of successful breastfeeding initiation, especially nursing exclusively at the breast with a rate of about $68 \%$. Overall, $98.6 \%$ of women breastfeed, but not all exclusively at the breast, and just $1.4 \%$ weaned. In the USA, the rate of breastfeeding initiation lay between $48 \%$ and $90 \%$ in 2008 [11], with a $75 \%$ rate in the total US population based on the latest National Immunization Survey [6].

In contrast, an observational study can only infer but not prove causality. Nor can we be certain that the variables studied were truly independent of one another. Because we used a new method to define successful breastfeeding initiation, it is difficult to compare our results with those of other studies.

\section{Conclusions}

The maternity ward plays an important role in the prevalence and duration of breastfeeding. Early breastfeeding support can give women confidence in their ability to breastfeed exclusively without recourse to feeding aids or supplements. Primiparous women and women with prepregnant obesity require the most intensive support. Women who receive neuraxial anesthesia during labor are another 
group who need careful supervision in starting to breastfeed. Health professionals should be alerted to these documented correlations with impaired breastfeeding initiation. A maternity unit setting that promotes immediate skinto-skin contact and rooming-in for $24 \mathrm{~h} /$ day is an important additional environmental factor, reinforced by preventive training in latching on and dedicated nipple care.

Received May 11, 2012. Accepted September 27, 2012. Previously published online October 25, 2012.

\section{References}

[1] Ahluwalia IB, Morrow B, Hsia J. Why do women stop breastfeeding? Findings from the Pregnancy Risk Assessment and Monitoring System. Pediatrics. 2005;116:1408-12.

[2] Amir LH, Donath S. A systematic review of maternal obesity and breastfeeding intention, initiation and duration. BMC Pregnancy Childbirth. 2007;7:9.

[3] Anderson JW, Johnstone BM, Remley DT. Breast-feeding and cognitive development: a meta-analysis. Am J Clin Nutr. 1999;70:525-35.

[4] Baker JL, Gamborg M, Heitmann BL, Lissner L, Sørensen TI, Rasmussen KM. Breastfeeding reduces postpartum weight retention. Am J Clin Nutr. 2008;88:1543-51.

[5] Blair A, Cadwell K, Turner-Maffei C, Brimdyr K. The relationship between positioning, the breastfeeding dynamic, the latching process and pain in breastfeeding mothers with sore nipples. Breastfeed Rev. 2003;11:5-10.

[6] Breastfeeding Section on Collaborators, Johnston M, Landers S, Noble L, Szucs K, et al. Breastfeeding and the use of human milk. Pediatrics. 2012;129:e827-41.

[7] Chang ZM, Heaman MI. Epidural analgesia during labor and delivery: effects on the initiation and continuation of effective breastfeeding. J Hum Lact. 2005;21:305-14; quiz 15-9, 26.

[8] Chen A, Rogan WJ. Breastfeeding and the risk of postneonatal death in the United States. Pediatrics. 2004;113:e435-9.

[9] Collaborative Group on Hormonal Factors in Breast Cancer. Breast cancer and breastfeeding: collaborative reanalysis of individual data from 47 epidemiological studies in 30 countries, including 50302 women with breast cancer and 96973 women without the disease. Lancet. 2002;360:187-95.

[10] Cope MB, Allison DB. Critical review of the World Health Organization's (WHO) 2007 report on 'evidence of the long-term effects of breastfeeding: systematic reviews and meta-analysis' with respect to obesity. Obes Rev. 2008;9:594-605.

[11] Cramton R, Zain-Ul-Abideen M, Whalen B. Optimizing successful breastfeeding in the newborn. Curr Opin Pediatr. 2009;21:386-96.

[12] Dennis CL. Breastfeeding initiation and duration: a 1990-2000 literature review. J Obstet Gynecol Neonatal Nurs. 2002;31: 12-32.

[13] DiGirolamo A, Thompson N, Martorell R, Fein S, GrummerStrawn L. Intention or experience? Predictors of continued breastfeeding. Health Educ Behav. 2005;32:208-26.

[14] Duijts L, Jaddoe VW, Hofman A, Moll HA. Prolonged and exclusive breastfeeding reduces the risk of infectious diseases in infancy. Pediatrics. 2010;126:e18-25.

[15] Gartner LM, Morton J, Lawrence RA, Naylor AJ, O’Hare D, Schanler RJ, et al. Breastfeeding and the use of human milk. Pediatrics. 2005;115:496-506.

[16] Hilson JA, Rasmussen KM, Kjolhede CL. Excessive weight gain during pregnancy is associated with earlier

termination of breast-feeding among White women. J Nutr. 2006;136:140-6.

[17] Institute of Medicine (US) and National Research Council (US) Committee to Reexamine IOM Pregnancy Weight Guidelines. Weight gain during pregnancy: reexamining the guidelines. Approaches to achieving recommended gestational weight gain. In: Rasmussen KM, Yaktine AL, editors. Washington, DC: National Academies Press; 2009.

[18] Karabulut E, Yalçin SS, Ozdemir-Geyik P, Karaağaoğlu E. Effect of pacifier use on exclusive and any breastfeeding: a meta-analysis. Turk J Pediatr. 2009;51:35-43.

[19] Katz KA, Nilsson I, Rasmussen KM. Danish health care providers' perception of breastfeeding difficulty experienced by women who are obese, have large breasts, or both. J Hum Lact. 2010;26:138-47.

[20] La Coursiere DY, Baksh L, Bloebaum L, Varner MW. Maternal body mass index and self-reported postpartum depressive symptoms. Matern Child Health J. 2006;10:385-90.

[21] Li DK, Willinger M, Petitti DB, Odouli R, Liu L, Hoffman HJ. Use of a dummy (pacifier) during sleep and risk of sudden infant death syndrome (SIDS): population based case-control study. Br Med J. 2006;332:18-22.

[22] Merten S, Dratva J, Ackermann-Liebrich U. Do baby-friendly hospitals influence breastfeeding duration on a national level? Pediatrics. 2005;116:e702-8.

[23] Mok E, Multon C, Piguel L, Barroso E, Goua V, Christin P, et al. Decreased full breastfeeding, altered practices, perceptions, and infant weight change of prepregnant obese women: a need for extra support. Pediatrics. 2008;121: e1319-24.

[24] Moore ER, Anderson GC. Randomized controlled trial of very early mother-infant skin-to-skin contact and breastfeeding status. J Midwifery Womens Health. 2007;52:116-25.

[25] Nysaether H, Baerug A, Nylander G, Klepp KI. Rooming-in in the maternity ward - are mothers satisfied? Tidsskr Nor Laegeforen. 2002;122:1206-9.

[26] O'Connor NR, Tanabe KO, Siadaty MS, Hauck FR. Pacifiers and breastfeeding: a systematic review. Arch Pediatr Adolesc Med. 2009;163:378-82.

[27] Parikh NI, Hwang SJ, Ingelsson E, Benjamin EJ, Fox CS, Vasan RS, et al. Breastfeeding in infancy and adult cardiovascular disease risk factors. Am J Med. 2009;122:656-63.

[28] Parsons TJ, Power C, Logan S, Summerbell CD. Childhood predictors of adult obesity: a systematic review. Int J Obes Relat Metab Disord. 1999;23:S1-107.

[29] Rasmussen KM, Hilson JA, Kjolhede CL. Obesity may impair lactogenesis II. J Nutr. 2001;131:3009S-11S.

[30] Rasmussen KM, Kjolhede CL. Prepregnant overweight and obesity diminish the prolactin response to suckling in the first week postpartum. Pediatrics. 2004;113:e465-71. 
[31] Rosenblatt KA, Thomas DB. Lactation and the risk of epithelial ovarian cancer. The WHO Collaborative Study of Neoplasia and Steroid Contraceptives. Int J Epidemiol. 1993;22:192-7.

[32] Rowe-Murray HJ, Fisher JR. Baby friendly hospital practices: cesarean section is a persistent barrier to early initiation of breastfeeding. Birth. 2002;29:124-31.

[33] Saarinen UM, Kajosaari M. Breastfeeding as prophylaxis against atopic disease: prospective follow-up study until 17 years old. Lancet. 1995;346:1065-9.

[34] UNICEF/WHO. Baby-friendly hospital initiative: revised, updated and expanded for integrated care. Section 1, Background and implementation. 1st ed. Geneva: WHO Document Production Services; 2009.
[35] WHO. Infant and young child feeding: model chapter for textbooks for medical students and allied health professionals; 2009.

[36] WHO, Expert Committee on Physical Status. The use and interpretation of anthropometry: report of a WHO expert committee. Geneva, Switzerland: World Health Organization; 1995.

[37] Wiklund I, Norman M, Uvnäs-Moberg K, Ransjö-Arvidson AB, Andolf E. Epidural analgesia: breast-feeding success and related factors. Midwifery. 2009;25:e31-8.

[38] Zimmermann R, Blöchlinger B, Kurmanavicius J. The electronic maternity notes. Gynäkologe. 2006;39:278-82.

The authors stated that there are no conflicts of interest regarding the publication of this article. 